\title{
The Influence of Technological Innovation on Urbanization Quality: A Case Study of Chinese Innovative Cities
}

\author{
Biying $\mathrm{Li}^{1,}$, , Ning Wang ${ }^{2}$, b \\ ${ }^{1}$ School of Shandong University of Science and Technology, Shandong 266590, china \\ ${ }^{2}$ School of Shandong University of Science and Technology, Shandong 266590, china \\ abeing_li1995@126.com, b2402008242@qq.com
}

Keywords: Urbanization quality; Technological innovation; Innovative city, cluster analysis regression model; science and technology financial expenditure

\begin{abstract}
Technological innovation, as the primary productive forces, plays an important role in the urbanization process. We attempted to explore the relation between technological innovation and urbanization quality so as to find how to expedite urbanization process through technological innovation. In this paper, we used innovative city as our research object and created technology innovative evaluation system. Combined with cluster analysis, samples were divided into three classes for comparison purpose. To investigate the mechanism of technological innovation's effect, we constructed two regression models. Our results demonstrate technological innovation has significant positive correlation to the improvement of urbanization quality. Among all the factors, STF, R\&D and TMT are the three major factors to influence the urbanization quality. The new and original in this paper is using two models to analyze the influence of technological innovation on urbanization quality.
\end{abstract}

\section{Introduction}

Since China implemented a historic reform and opening up policies in 1978, accompanied by the accelerating industrialization process, urbanization in our country went through a low starting-point, rapid-development period. From 1978 to 2013, the population of permanent residents in cities and towns has risen from 170 million to 730 million, the urbanization rate from $17.9 \%$ to $53.7 \%$, raised by 1.02\% per year; the number of city has increased from 193 to 658, and town from 2173 to 20113. Although from the standards of the urbanization rate, China, on the whole, has turned into the primary urban society. But from lifestyle, culture as well as urban and rural coordination standards, we still have a long way to go. Hence the urbanization level maintains rapid growth, but urbanization quality has not increased at the same time ${ }^{[1]}$.

In recent years, a large number of scholars studying the urbanization quality from different perspectives, such as Dai Yongan $(2010)^{[2]}$ and li hongbo(2011 $)^{[3]}$, investigated the efficiency of urbanization from the different aspects of "population, economy, society" and "resource intensive, modernization of cities, integration of urban and rural areas". FANG Chuang Lin (2011) made overall evaluation on Chinese urbanization quality and spatial differentiation ${ }^{[4]}$. He develops 3 types of indicators and 12 specific indicators from three aspects. Although scholars study in many different perspectives, it largely enriches the urbanization evaluation system and provides more specific ideas to the later studies.

The technological innovation is the ability that constantly keeps the knowledge, technology, information into the production process. Technological innovation ability is the comprehensive reflection of knowledge and technology development. In other words, the degree of technological innovation directly affecting the city's technology level exerts certain effects on the efficiency of urbanization quality. In HaoShouyi's(2012) study, he pointed out the technological innovation and the level of urbanization affect the economic growth of the city in different extent ${ }^{[5]}$, but he did not make it clear whether there is a correlation between technological innovation and urbanization. In the study of FanJian (2008), he believes that economic development level, industrialization, technological innovation, economic openness are the four main factors to influence the urbanization process $^{[6]}$. He also considered technological innovation is the source of power for modern city. 
Hence we can see technological innovation is the key element that affects the urbanization process, which plays a crucial part in the urban construction and development.

\section{Selections of the samples and analysis of urbanization quality}

\section{1 selections of the samples}

Nowadays, China is getting down building innovative cities. Since the nation's medium and long term plan for the development of science and technology, the ministry has approved 57 cities as national innovation pilot cities. An innovative city is characterized by independent innovation ability, high-level of sustainable development of social economic, and regionally significant driving and radiating forces. Accelerating the innovative city construction is of great significance for enhancing independent innovation ability, speeding up the transformation of economic development patterns, promoting sound and rapid regional economic and social development and building an innovation-oriented country. The national innovation unit is a good representative to this study. Due to the restriction of the data and the urban layout, we selected the 39 national innovative cities as our samples.

\section{2 analysis of the samples' urbanization quality}

The China economic weekly, published by the institute of urban development and environment in the Chinese Academy of Social Sciences(CASS), explored the evaluation system of urbanization in China in depth. And it got the basic information and the rank of prefecture-level city's urbanization quality, based on the data in 2012. The measurement index of urbanization, in this thesis, comes from their research findings.

Table 1 urbanization quality score of all innovative cities

\begin{tabular}{|c|c|c|c|c|c|c|c|c|}
\hline City & $\begin{array}{c}\text { Urbanization } \\
\text { quality }\end{array}$ & rank & City & $\begin{array}{c}\text { Urbanizatiaon } \\
\text { quality }\end{array}$ & rank & City & $\begin{array}{c}\text { Urbanization } \\
\text { quality }\end{array}$ \\
\hline Shijiazhuang & 50.68 & 30 & Taiyuan & 52.01 & 26 & Nanning & 47.39 \\
\hline Tangshan & 54.71 & 21 & Haerbin & 51.99 & 27 & Baoji & 46.85 & 34 \\
\hline Shenyang & 60.43 & 12 & Jingdezhen & 44.06 & 39 & Kunming & 46.98 & 36 \\
\hline Changzhou & 63.63 & 5 & Nanchang & 48.48 & 32 & Guiyang & 51.49 & 28 \\
\hline Lianyungang & 47.26 & 35 & Luoyang & 48.42 & 33 & Huhehaote & 52.18 & 25 \\
\hline Zhenjiang & 57.57 & 17 & Wuhan & 58.46 & 15 & Dalian & 62.65 & 6 \\
\hline Ningbo & 59.35 & 13 & Changsha & 60.67 & 10 & Changchun & 52.96 & 24 \\
\hline Jiaxing & 59.18 & 14 & Hefei & 55.39 & 20 & Zhengzhou & 51.19 & 29 \\
\hline Xiamen & 65.26 & 2 & Chengdu & 61.51 & 9 & Nantong & 57.8 & 16 \\
\hline Fumen & 54.19 & 22 & Lanzhou & 49.93 & 31 & Yangzhou & 57.47 & 19 \\
\hline Jinan & 60.54 & 11 & Xining & 44.95 & 38 & Hangzhou & 62.18 & 8 \\
\hline Guangzhou & 64.84 & 3 & Yinchuan & 54.11 & 23 & Qingdao & 62.21 \\
\hline Nanjing & 63.76 & 4 & Xian & 57.56 & 18 & Shenzhen & 77.63 & 7 \\
\hline
\end{tabular}

\section{Technological innovative capability}

\section{1 technology innovative evaluation system}

By Setting up evaluation system of technological innovation, the city's technological innovation ability can be assessed standardly and effectively. Based on the study of the scholars to establish technology innovative evaluation system and the designing principle to evaluate indicator system, we design technological innovation systems of the innovative city as follows: 
Table 2 technology innovative evaluation system

\begin{tabular}{cc}
\hline $\begin{array}{c}\text { Technology development } \\
\text { capability }\end{array}$ & $\begin{array}{c}\text { the number of R\&D }\left(\mathrm{V}_{1}\right) \\
\text { the number of educate }\left(\mathrm{V}_{2}\right)\end{array}$ \\
\hline $\begin{array}{c}\text { technological innovative } \\
\text { investment capability }\end{array}$ & $\begin{array}{c}\text { whole society R\&D spending }\left(\mathrm{V}_{3}\right) \\
\text { science and technology financial expenditure }\left(\mathrm{V}_{4}\right)\end{array}$ \\
\cline { 2 - 2 } $\begin{array}{c}\text { Technology innovation } \\
\text { achievements }\end{array}$ & the number of application for patents $\left(\mathrm{V}_{5}\right)$ \\
& Technical market turnover $\left(\mathrm{V}_{6}\right)$ \\
High-tech industrial output value $\left(\mathrm{V}_{7}\right)$ \\
the number of paper $\left(\mathrm{V}_{8}\right)$
\end{tabular}

We adopt the factor analysis to automatically generate weight coefficient, so as to avoid negative consequences that the subjective factors cause. The data are selected from each city's Annals of Statistics and Annals of Statistics science and technology in 2012. Due to the limitations of data collection, we simply select 39 cities from all the innovative cities. On the basis of factor analysis, we analyze the components of 39 innovative city's technological innovation ability using SPSS, finding the formula of composite scores are listed as follows:

$$
\mathrm{Y}=43.090 \mathrm{~F} 1+22.196 \mathrm{~F} 2+18.380 \mathrm{~F} 3
$$

In order to calculate the next step conveniently, based on the $3 \sigma$ principle, we use formula $\mathrm{Yt}=\mathrm{H}+\alpha \mathrm{Y}$ to eliminate the negative influence by conducting coordinate translation. Then we acquire scores which are as follows:

Table 3 technology innovative evaluation scores

\begin{tabular}{|c|c|c|c|c|c|c|c|c|}
\hline city & $\begin{array}{c}\text { Total score after } \\
\text { coordinate translation }\end{array}$ & rank & city & $\begin{array}{c}\text { Total score after } \\
\text { coordinate translation }\end{array}$ & rank & city & $\begin{array}{c}\text { Total score after } \\
\text { coordinate translation }\end{array}$ & rank \\
\hline Shijiazhuang & 13.32618 & 32 & Taiyuan & 23.01434 & 8 & Nanning & 12.45682 & 36 \\
\hline Tangshan & 12.09398 & 39 & Haerbin & 17.70385 & 22 & Baoji & 12.27075 & 38 \\
\hline Shenyang & 21.39864 & 12 & Jingdezhen & 12.80387 & 34 & Kunming & 14.45886 & 30 \\
\hline Changzhou & 24.91353 & 4 & Nanchang & 15.51863 & 27 & Guiyang & 15.27155 & 28 \\
\hline Lianyungang & 14.45999 & 29 & Luoyang & 13.37462 & 31 & Huhehaote & 12.70939 & 35 \\
\hline Zhenjiang & 22.51084 & 9 & Wuhan & 23.3731 & 6 & Dalian & 20.22048 & 15 \\
\hline Ningbo & 19.61783 & 17 & Changsha & 21.85666 & 11 & Changchun & 15.73097 & 26 \\
\hline Jiaxing & 18.01489 & 21 & Hefei & 20.86901 & 13 & Zhengzhou & 16.70454 & 24 \\
\hline Xiamen & 23.26034 & 7 & Chengdu & 19.86475 & 16 & Nantong & 18.84049 & 18 \\
\hline Fumen & 15.911 & 25 & Lanzhou & 17.04868 & 23 & Yangzhou & 18.1272 & 20 \\
\hline Jinan & 20.25467 & 14 & Xining & 12.29333 & 37 & Hangzhou & 24.82547 & 5 \\
\hline Guangzhou & 22.24624 & 10 & Yinchuan & 13.01121 & 33 & Qingdao & 18.81764 & 19 \\
\hline Nanjing & 29.35336 & 2 & Xian & 25.21342 & 3 & Shenzhen & 34.40189 & 1 \\
\hline
\end{tabular}

In order to test the validity of this method, we carry on the KMO and Bartlett KMO test .KMO= $0.774>0.7$, it belongs to general inspection. At the same time, the Bartlett Sphericity test value is 327.933, sig. $=0.0000<0.01$. It rejects the null hypothesis that correlation matrix is Unit matrix and indicates that validation passes, so it's reasonable to conduct factor analysis.

\subsection{Cluster analysis}

According to the scores above, we analyze each city's Q cluster using SPSS, and then get the results as below: 
Table 4 conclusions of Cluster analysis

\begin{tabular}{|c|c|c|}
\hline Cities & \multicolumn{2}{|c|}{$\begin{array}{l}\text { Shijiazhuang, Tangshan, Lianyungang, Fuzhou,Haerbin, Jingdezhen, Nanchang, Luoyang, } \\
\text { Lanzhou, Xining, Yinchuan, Nanning, Baoji, Kunming, Guiyang, Huhehaote, Changchun, } \\
\text { Zhengzhou. }\end{array}$} \\
\hline \multicolumn{2}{|r|}{ The mean value of technical innovation capability evaluation } & 14.29 \\
\hline \multicolumn{3}{|c|}{ It is the lowest level in three classes, especially there is the deep gap in $h$} \\
\hline Cities & \multicolumn{2}{|c|}{$\begin{array}{l}\text { Shenyang,Changzhou,Zhenjiang,Jiaxing,Ningbo,Xiamen,Jinan,Guangzhou,Taiyuan, Wuhan,Chang } \\
\text { sha,Hefei,Chengdu,Xi'an,Dalian,Nantong,Yangzhou,Hangzhou, Qingdao. }\end{array}$} \\
\hline \multicolumn{2}{|r|}{ The mean value of technical innovation capability evaluation } & 21.43 \\
\hline \multicolumn{3}{|c|}{$\begin{array}{l}\text { It is the medium level in the three classed Compared with the third category, the number of application for } \\
\text { patent and high-tech industrial output value accounting for the proportion of industrial productions are lower. }\end{array}$} \\
\hline Cities & \multicolumn{2}{|l|}{ Nanjing,Shenzhen } \\
\hline \multicolumn{2}{|r|}{ The mean value of technical innovation capability evaluation } & 31.878 \\
\hline \multicolumn{3}{|c|}{$\begin{array}{l}\text { Shenzhen's technology innovation ability evaluation is } 34.402 \text {, is about } 2.5 \text { times of the first class of cities, } \\
\text { and the Nanjing's technological innovation ability evaluation index is } 29.354 \text {. There is also a certain gap with the } \\
\text { technological innovation ability of Shenzhen city. Shenzhen city, which is the first pilot as an innovative city, } \\
\text { with a strong momentum to promote the development of technological innovation, exceeds other cities. }\end{array}$} \\
\hline
\end{tabular}

\subsection{Analysis Characteristics classification}

According to classification in chapter 5, now we respectively analyze technological innovation ability of all kinds of city. Evaluate the mean of each assessment index, calculate each class's disparity, and then obtain the following results:

Ps: Cv1 is coefficient variation between the first category and the second category

Cv2 is coefficient variation between the second category and the third category

Cv3 is coefficient variation between the first category and the third category

Table 5 analysis of classification

\begin{tabular}{|l|l|c|c|c|c|c|}
\hline & $\begin{array}{c}\text { the first } \\
\text { category }\end{array}$ & $\begin{array}{c}\text { the second } \\
\text { category }\end{array}$ & $\begin{array}{c}\text { the third } \\
\text { category }\end{array}$ & Cv1 & Cv2 & Cv3 \\
\hline V1 & 202.3273 & 321.6454 & 538.78 & 0.589728 & 0.675074 & 1.662913 \\
\hline V2 & 1181.519 & 1572.027 & 1949.28 & 0.330514 & 0.239979 & 0.649808 \\
\hline V3 & 1.127489 & 2.40097 & 3.32 & 1.129484 & 0.382774 & 1.944596 \\
\hline V4 & 1.519409 & 3.302891 & 4.8 & 1.1738 & 0.453272 & 2.159123 \\
\hline V5 & 93.98316 & 252.6878 & 892.92 & 1.68865 & 2.533689 & 8.500851 \\
\hline V6 & 0.713524 & 1.124539 & 1.51 & 0.576035 & 0.342772 & 1.116257 \\
\hline V8 & 8.209138 & 13.16034 & 39.76 & 0.603133 & 2.021199 & 3.843383 \\
\hline
\end{tabular}

According to the technology innovative evaluation system and the chart above, the disparity of all classes of technological innovation ability mainly lies in the technology innovative achievements and its transformation, or to say the number of application for patents and High-tech industrial output value .The gap of technology development skills and technological innovation investment are small ,especially the former. So, the basic level and inputs of all classes are similar. The main reasons for this difference is the technology innovative achievements and its transformation .Thus to improve the technological innovation ability of the city, the main point is to speed up the transformation of technological innovation, instead of just increasing investment in infrastructure. 


\section{Technological innovation and urbanization quality}

\section{1 setting up the model}

In this paper, we probe into the problem whether the innovative cites' technological innovation ability difference will influence urbanization quality, and explore the extent of its influence as well. According to the data above, we develop the first regression model by using urbanization quality (URBQ) as the explained variable and the technological innovation ability (TIA) as the explanatory variable to explore the relation between technological innovation and urbanization quality and the influence mechanism.

From technology innovative evaluation system, we can evaluate technology innovative capacity in three aspects, including technology development ability, technological innovation investment, technological innovation achievement, as well as the relevant of 8 indicators. According to the correlation of the urbanization quality and indicators in technology innovative evaluation system, we respectively select several indicators that are of high correlation and explainable from three aspects. The second regression model is established with URBQ as the explained variable, STF, TMT, R\&D as the explanatory variables to find out the main factors to the quality of urbanization. There are two regression models:

$$
\begin{gathered}
\ln U R B Q=\beta 0+\beta 1 \ln T I A \\
\ln U R B Q=\beta 0+\beta 1 \ln S T F+\beta 2 \ln T M T+\beta 3 \ln R \& D
\end{gathered}
$$

\subsection{Selection of the indicator}

All the data are from China statistical Yearbook

(1)URBQ: Urbanization Quality is the qualitative indicator that measures the process of urbanization. It reflects the efficiency and results of urbanization. The China economic weekly, published by the institute of urban development and environment in the Chinese Academy of Social Sciences(CASS), explored the quality evaluation system of urbanization in China in depth. And it got the basic information and the rank of prefecture-level city's urbanization quality, based on the data in 2012.The measurement indicators of urbanization in this paper are from their research findings.

(2) TIA: the technological innovation ability. The data are from the marks of 39 innovative cities that we explore based on technology innovative evaluation system.

(3) STF: science and technology financial expenditure, which is used to measure a region's the investment of science and technology. The expenditure of technology refers to the expenditure for science and technology.

\section{Formula:}

(Science and technology financial expenditure /fiscal expenditure)*100\%

(4)TMT: Technical market turnover as a share of GDP is used to measure the achievements of a region's technological innovation.

\section{Formula:}

(Technical market turnover /GDP) * 100\%

(5)R\&D: the number of $R \& D$ per 10 thousand employers is used to measure a region's technological innovation development ability.

\section{Formula:}

(the number of R\&D / the number employers)*10000

\subsection{The analysis of the result}


Table 6 Coefficients between TIA and URBQ

\begin{tabular}{|c|c|c|c|c|c|c|}
\hline & \multirow{2}{*}{ Model } & \multicolumn{2}{|c|}{ Unstandardized Coefficients } & \multirow{2}{*}{$\begin{array}{c}\text { Standardized Coefficients } \\
\text { Beta }\end{array}$} & \multirow{2}{*}{$t$} & \multirow{2}{*}{ Sig. } \\
\hline & & B & Std. Error & & & \\
\hline \multirow{2}{*}{1} & (Constant) & 2.892 & .121 & & 23.914 & .000 \\
\hline & TIA & .388 & .042 & .838 & 9.324 & .000 \\
\hline
\end{tabular}

a. Dependent Variable: URBQ

Table 6 is the regression result of model (1). Technological innovation has significant positive correlation to the improvement of urbanization quality in linear relation. The regression equation is $\mathrm{Y}=34.297+1.154 \mathrm{X}$.

Table 7 Coefficients between all variables and URBQ

\begin{tabular}{|c|c|c|c|c|c|c|c|}
\hline VARIABLE & $\begin{array}{c}\text { urbanization } \\
\text { quality }\end{array}$ & VARIABLE & $\begin{array}{c}\text { urbanization } \\
\text { quality }\end{array}$ & VARIABLE & $\begin{array}{c}\text { urbanization } \\
\text { quality }\end{array}$ & VARIABLE & $\begin{array}{c}\text { urbanization } \\
\text { quality }\end{array}$ \\
\hline V1 & $0.631 * *$ & V2 & $0.346^{*}$ & V3 & $0.373^{*}$ & V4 & $0.722^{* *}$ \\
\hline V5 & $0.789 * *$ & V6 & $0.518^{* *}$ & V7 & 0.274 & V8 & -0.008 \\
\hline
\end{tabular}

In order to show the correlation between urbanization quality and other factors, we need to calculate the variables' Person correlation coefficient. As shown in Table 7, urbanization quality shows the positive correlation with $\mathrm{V}_{4}(\mathrm{STF}), \mathrm{V}_{6}(\mathrm{TMT})$ and $\mathrm{V}_{1}(\mathrm{R} \& D)$. Other indicators are not so clear. Therefore, when we explore the urbanization quality and the influence mechanism of technological innovation or other factors, there is no sense to research and analyze other indicators.

Table 8 Coefficients between three variables and URBQ

\begin{tabular}{|c|c|c|c|c|c|}
\hline \multirow{2}{*}{ Model } & \multicolumn{1}{|c|}{ Unstandardized Coefficients } & Standardized Coefficients & \multirow{2}{*}{ t } & Sig. \\
\hline (Constant) & B & Std. Error & Beta & \\
\hline STF & .123 & .476 & .027 & 18.405 & .000 \\
\hline TMC & .029 & .013 & .573 & 4.621 & .000 \\
\hline R\&D & .082 & .036 & .229 & 2.241 & .031 \\
\hline
\end{tabular}

Table 8 is the regression result of model (2).The logarithm of urbanization quality is explained variable regression. The results indicate three aspects are significant in $5 \%$ level and they are all positive. Three aspects are $\mathrm{V}_{4}(\mathrm{STF}), \mathrm{V}_{6}(\mathrm{TMT})$ and $\mathrm{V}_{1}(\mathrm{R} \& D)$. In an innovative city, it has a significantly positive promoting effect on the quality of urbanization by increasing science and technology financial expenditure and the number of $R \& D$, and speeding up the transformation of science and technology. It shows regression coefficient of STF is bigger than R\&D, and regression coefficient of $R \& D$ is bigger than TMC. To an extent, it reflects that STF impact on the urbanization quality is greater than R\&D's and TMC.

\section{Conclusion and suggestion}

In this paper, we regard 39 innovative cities as our research object, analyzing the relationship between technological innovation and urbanization quality. We evaluate technological innovation and rank the 39 cities, and carry on clustering analysis. We divide those cities into three levels. 
Then we select indicators relevant to the urbanization quality, and establish two regression models, respectively, from the three levels of technological innovation. We probe into the impact of technological innovation ability on urbanization quality.

(1)In the cluster analysis of technology innovative evaluation system, we divide 39 samples into three levels and find the gap between the three levels, actually are small in technological innovation development and technological innovation investment. So, each city's development condition is similar. The evident disparity mainly embodies in the technological innovation achievements and its transformation, especially in the index that the number of application for patents and high-tech industrial output value. Thus to improve the technological innovation ability of the city, we should not to blindly increase input in infrastructure and investment in financial, but to speed up the transformation and application of technological innovation achievements.

(2) Technological innovation plays a significant positive role in promoting urbanization quality. Urbanization quality shows the positive correlation with STF, TMC and R\&D. But the significance of other indicators is not obvious.

(3)In the study of the main factors that affect urbanization quality, we should increase science and technology financial expenditure, and the number of R\&D, and speed up the transformation of science and technology to enhance the urbanization quality. And the STF impact on urbanization quality is larger than R\&D's and TMC.

The following recommendations can be listed on the construction of the urbanization quality in china:

(1) In the process of urbanization, the blind pursuit of higher proportion of the urban population, not only will make it difficult to integrate a large number of population who engage in agricultural work into urban society, causing tremendous economic and social development risks and hazards, but the urban population will surpass the total carrying capacity, resulting in the increase of economic, social and ecological costs. Therefore, improving urbanization quality should be treated as the core impetus urge to promote the construction of urbanization.

(2)The innovation investment and the basic environment of each innovative city are roughly similar. The difference between urban technology innovative ability mainly lies in the use of investment in technological innovation. Thus to enhance urban technological innovation, we should not blindly introduce advanced talents or increase investment, but to consider how to take advantage of the current resources and funding, how to promote the use and transformation of technological innovation.

(3)The development of urbanization in China and information technology should be at the same pace, and the improvement of urban technology innovative ability represents the advancements of information technology. So we should put enough emphasis on promoting the innovation ability when we enhance the urbanization construction. Therefore, various innovative cities can improve urbanization quality by increasing expenditures in science technology, enhancing R\&D personnel training, accelerating the transformation of science and technology.

\section{References}

[1]. Zhao Liming. Cities Innovation System [M]. Tianjin: Tianjin University Press, 2002. (In Chinese)

[2]. Dai yongan. Efficiency of China's urbanization and its influencing factors - based on analysis of stochastic frontier production function[J] research of numerical technical Economics, 2010,12: 103-117 + 132. (In Chinese)

[3]. LI Hongbo, Zhang Xiaolin .Study of new urbanization connotation and Measure methods of China's developed areas - A Case Study in Jiangsu Province [J], 2011, 06: 60-64. (In Chinese)

[4]. FANG Chuang Lin, Wang Deli .Comprehensive measure of China's urbanization development quality and enhance the path [J] Geographical Research, 2011, 11: 1931-1946. R. Nicole, "Title of paper with only first word capitalized,” J. Name Stand. Abbrev, in press. (In Chinese) 
[5]. Hao shouyi, Fan xiaoli. The level of urbanization, Technological Innovation and Urban Economic Growth - based on the Empirical Study of 25 cities' Panel Data [J] Modern Management Science, 2012,01: 74-76. (In Chinese)

[6]. FAN Jian. Research of factors affecting urbanization [D]. Lanzhou University, 2008 (In Chinese) 